\title{
Hacia una educación pertinente: percepciones de los estudiantes de grado undécimo en la localidad séptima de Bogotá (Bosa)
}

Towards a relevant education: perceptions of eleventh grade students in the seventh locality of Bogotá (Bosa)

Juan Carlos Piñeros Suárez ${ }^{1}$ Secretaría de educación de Bogotá

Recibido: 27.04.2021

Aceptado: 30.06.2021

\section{Resumen}

El presente artículo hace parte de los resultados que expone la investigación concluida "Pedagogía de la biomotricidad: orientaciones didácticas basadas en el buen vivir". Se describe una reflexión, la cual se desarrolla con base en el primer objetivo de la investigación "Conocer las principales motivaciones que llevan a los estudiantes de grado undécimo de la Localidad Séptima de Bogotá (LSB) a asistir a la escuela”. Desde esta perspectiva, se plantea un cuestionario abierto con 13 preguntas que pretenden recoger las impresiones de los estudiantes de grado undécimo en la (LSB), en relación con sus intencionalidades para asistir a la escuela y aquellos elementos que pueden disminuir la participación de los jóvenes en las diferentes sesiones de trabajo. Se evalúa como unidad de análisis 7 mega colegios de la localidad, seleccionando aleatoriamente un grado undécimo por cada plantel educativo para la aplicación de la encuesta. La investigación se estructura desde un presupuesto epistémico

\footnotetext{
1 jcpineros@educacionbogota.edu.co
} https://orcid.org/0000-0001-9905-9317

Volumen 2. Número 1. Enero - Junio 2022 
denominado interaccionismo simbólico, ya que se busca comprender e interpretar las realidades que se presentan en la interacción de los estudiantes en el proceso de enseñanza, saber y aprendizaje y sus manifestaciones desde la percepción de los estudiantes. La información recolectada, se sistematiza bajo el diseño metodológico denominado "teoría fundamentada" generando la categoría de análisis (Motivaciones Para Asistir a Clase (MPAC), Buen vivir (BV) y pedagogía y didáctica (PD) con sus respectivas recomendaciones derivadas de la interrelación, teoría, categorización de los datos y trabajo vivencial del investigador.

Palabras clave: Aprendizaje, colegios públicos, motivaciones, emoción, ética.

\section{Abstract}

This article is part of the results of the completed research "Pedagogy of biomotor skills: didactic guidelines based on good living." A reflection is described, which is developed based on the first objective of the research "To know the main motivations that lead eleventh grade students from the Seventh Town of Bogotá (LSB) to attend school". From this perspective, an open questionnaire is proposed with 13 questions that seek to collect the impressions of eleventh grade students in the (LSB), in relation to their intentions to attend school and those elements that can reduce the participation of young people in the different work sessions. 7 mega schools in the locality are evaluated as the unit of analysis, randomly selecting an eleventh grade for each educational establishment for the application of the survey. The research is structured from an epistemic assumption called symbolic interactionism, since it seeks to understand and interpret the realities that arise in the interaction of students in the teaching, knowledge and learning process and its manifestations from the students' perception. The information collected is systematized under the methodological design called "grounded theory" generating the category of analysis (Motivations To Attend Class (MPAC), Good Living (BV) and pedagogy and didactics (PD) with their respective recommendations derived from the interrelation, theory, categorization of data and experiential work of the researcher. 
Keywords: Learning, public schools, motivations, emotion, ethics

\section{Introducción}

Las diferentes realidades contextuales que se evidencian en las comunidades educativas de grado undécimo y las percepciones que pueden llegar a consolidar los estudiantes universitarios desde sus vivencias en el entorno escolar, son factores determinantes a la hora de proponer un proceso pedagógico que responda a las necesidades que emergen en una sociedad globalizada. En este sentido, el educador desde una perspectiva integral debe conocer a profundidad los aspectos socioemocionales, los niveles de comprensión, las formas de aproximarse que tienen los estudiantes frente al conocimiento y las posibilidades de aprendizaje que pueden emerger desde el saber pedagógico. Desde esta perspectiva, en esta investigación se indaga sobre las principales motivaciones que llevan a los estudiantes de grado undécimo a asistir a los planteles educativos distritales en la Localidad Séptima de Bogotá (LSB), con la intención de generar un consolidado pedagógico y didáctico que responda a estas necesidades y permita establecer una guía o unas orientaciones, que puedan ser consideradas en una educación pertinente.

\section{Problemáticas que afectan a los estudiantes}

Entender la complejidad de la persona que aprende es el primer paso para identificar los aspectos relevantes que deben ser abordados al considerar una corriente pedagógica contemporánea, tal como lo plantean Hurtado \& Tercero, (2010) quienes afirman que "las Corrientes Pedagógicas Contemporáneas como las representaciones conceptuales o teorías pedagógicas que surgen de la realidad, planteando los elementos que debe tener una pedagogía, fundamentándose en teorías psicológicas, sociológicas y antropológicas, considerando la multidimensionalidad del hombre" (p.81). Así mismo, delimitar las principales problemáticas que expresan los estudiantes desde sus percepciones puede permitir clasificar y caracterizar las necesidades educativas desde esta mirada en particular. 
Una de las primeras nociones caracterizadas en la investigación es el abordaje de los contenidos disciplinares de una forma estricta y con poco interés por parte del docente en relación con el aspecto motivacional. Es decir, la ausencia de un dialogo con el estudiante en la revisión del contenido que va a ser abordado por parte del maestro con miras a estimular la participación de los jóvenes desde sus saberes. En este sentido expresa Neira, (2010) que:

Cuando el profesor concibe todos los alumnos de la misma manera, con saberes y necesidades semejantes, termina por eximirse de la responsabilidad de diferenciar el currículo y las relaciones establecidas durante las actividades de enseñanza. Tal daltonismo obstaculiza el aprovechamiento de la riqueza constatada en la diversidad de símbolos, significados, patrones de interpretación y manifestaciones culturales que cotidianamente nos interpelan. (p.58)

Esta problemática es recurrente en los planteamientos de los estudiantes evaluados en la investigación, quienes consideran que anexo a la ausencia de caracterización de las particularidades e individualidades al proponer el proceso de enseñanza, Algunas clases no tienen sentido ni relevancia desde el aspecto motivacional. Del mismo modo la dificultad que representan algunas asignaturas no permite llegar a la comprensión; lo cual es un factor que aumenta la desmotivación. Por último, "los estudiantes manifiestan que algunos docentes no hacen de sus clases momentos agradables y este factor influye en la participación" (Piñeros, 2019, p.156).

Desde esta perspectiva, pensar en un clima o ambiente agradable en el aula de clase se delimita como un condicionante necesario que permite optimizar los aprendizajes y motivar a los estudiantes en la asistencia y participación en las sesiones de trabajo. Otra problemática relevante expuesta por los estudiantes de grado undécimo en la (LSB) y relacionada con este clima escolar está enfocada a las "problemáticas de carácter personal e interpersonal como pereza, irrespeto por parte de los compañeros de estudio, malas relaciones familiares, pandillismo y drogadicción” (Piñeros, 2019, p.701). 
Estas situaciones concernientes al contexto no permiten que se obtengan de las clases una formación rigurosa, ya que los estudiantes que presentan estas problemáticas no evidencian gran interés en el aprendizaje e interrumpen el proceso de aquellos estudiantes que asisten con la necesidad de aprender. Esta perspectiva, que se encuentra ampliamente ligada al aspecto socioemocional de los niños específicamente desde la inteligencia personal, la cual es caracterizada por Gardner (1993) como la "habilidad para notar y esclarecer distinciones entre otros individuos y, en particular, entre sus estados de ánimo, temperamentos, motivaciones e intenciones" (p.288). Sin embargo, este aspecto socioemocional no es considerado de forma rigurosa en los colegios públicos evaluados como un componente determinante en la planeación ni en los contenidos que deben ser abordados en las áreas de conocimiento, considerando que el aspecto relevante del currículo está ligado a los "aspectos duros" de la educación (Santomé, 1998). Desde esta perspectiva socio emocional, los estudiantes de la (LSB) también evidencian como una problemática bastante compleja la falta de comprensión a nivel emocional que presentan sus docentes con relación a sus problemáticas personales, lo cual desmotiva en la asistencia a clases, ya que no se identifica la causa del bajo compromiso, pero continuamente se hacen comparativos a nivel intelectual sin considerar estas diferencias. En este sentido los estudiantes plantean que hay "poca motivación por parte de los docentes al plantear las clases" (Piñeros, 2019, p.705) y sugieren "La modificación de los métodos de enseñanza, desde unas explicaciones claras, acorde a los intereses de los estudiantes, con muy buenas herramientas emocionales por parte del docente como, respeto por la diferencia al aprender, paciencia, buen trato, vocación y liderazgo" (Piñeros, 2019, p.709).

Al caracterizar algunas de las dificultades que pueden afectar los procesos de enseñanza, saber y aprendizaje en los estudiantes de grado undécimo de la (LSB), se realiza una revisión rigurosa de los principales hallazgos en relación con estas problemáticas que afectan las realidades escolares (60 textos) y se indaga sobre algunas investigaciones desarrolladas que han considerado una mirada alternativa de la escuela desde el ámbito emocional, social y ético (60 textos). 
Figura 1. Parte del estado del arte

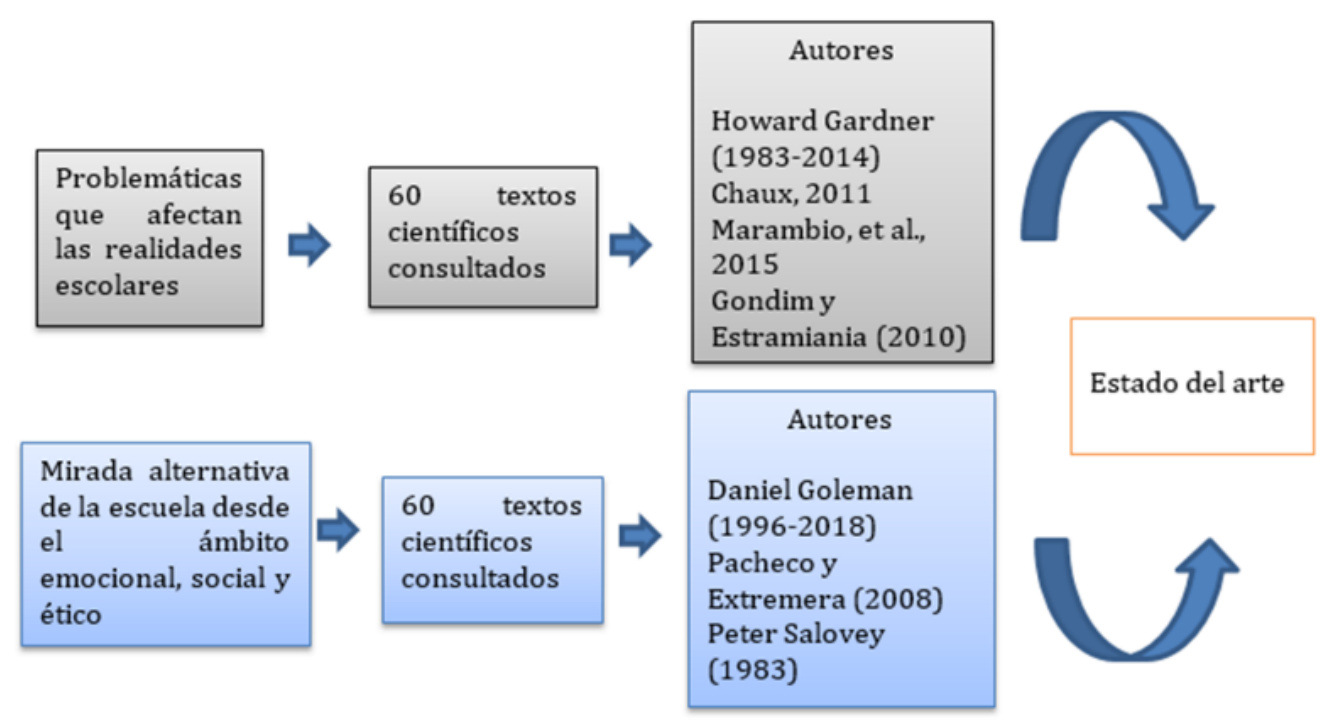

Este recorrido bibliográfico evidencia que la competitividad como un elemento característico de la educación tradicional disminuye la posibilidad que tienen los estudiantes de ser valorados por sus compañeros, ya que el proceso comparativo evaluado desde unas características deseadas solo reconoce algunos aspectos de la persona humana y deja de lado otras potencialidades que la educación academicista no tiene en cuenta. Por otro lado, se considera que el abordaje de la violencia escolar al interior de los planteles educativos es un factor que desafortunadamente no es considerado en la estructura curricular, lo cual coincide con las percepciones antes descritas por los estudiantes, y por lo tanto los plánteles educativos deberían considerar en sus planes de estudio y la reestructuración de sus disciplinas componentes direccionados al manejo de las emociones (Chaux, 2011). Por último, la recopilación bibliográfica deja en evidencia la necesidad de formar a los docentes en competencias socioemocionales como un aspecto relevante en los currículos universitarios ya que, a la hora de aplicar las prácticas de enseñanza en contextos vulnerables o con problemáticas contextuales complejas el docente adolece de competencias como empatía, asertividad o tolerancia al error y estos factores pueden afectar el aprendizaje (Piñeros, 2019). 


\section{Las emociones en la escuela}

Diferentes estadios en nuestra vida tales como la tristeza, la euforia, el placer, el miedo, la ira entre otras emociones, hacen parte de la cotidianidad y de las decisiones positivas y negativas que se toman a diario, en una primera etapa la emoción está relacionada con los aspectos fisiológicos básicos que determinan nuestras conductas y su respuesta a ellas desde el aspecto corporal, En palabras de (Kandel, Schwartz, \& Jessel, 1997)

Las emociones son respuestas cognitivas a la información que proceden de la periferia, experimentadas de una manera análoga al modo en que percibimos los pensamientos. Nuestra experiencia diaria confirma que la información procedente del cuerpo contribuye a la experiencia emocional. Por otra parte, los pacientes cuya medula espinal se ha seccionado accidentalmente, experimentan una reducción significativa de la intensidad de la emoción. Esta reducción correlaciona con el nivel espinal en el que ha tenido lugar la sección: cuanto más alto es el nivel de la sección, más se reduce la respuesta emocional. (p. 636)

Esta perspectiva constituye una primera mirada de las consideraciones que se deben tener en cuenta en el aula de clases al proponer diferentes apuestas educativas. Cada aspecto que moviliza nuestras emociones está ampliamente relacionado con un estadio corporal, que responde a una emoción en particular. En este sentido, el docente debe conocer cuáles son las principales percepciones que tienen sus estudiantes en relación con la temática planteada, los contenidos relevantes para su vida, las problemáticas que afectan sus aprendizajes, los distintos modos de aproximarse a los saberes y su rol como generador de emociones en el aula de clases. Ya que, el "cerebro decide a qué le prestamos atención. Como un poderoso reflector enfocado en el mundo exterior, este sistema de orientación selecciona, entre los millones de estímulos que nos bombardean, aquello a qué adjudicarle recursos mentales" (Dehaene, 2019, p.212). Es por esto por lo que se deben considerar algunas estrategias que nos permitan mejorar el ambiente en el aula de clases, estimulando emociones positivas que ayuden a los estudiantes a sentirse aceptado por sus compañeros de clase y profesores, a generar una 
correlación entre los aprendizajes y las actitudes frente a las apuestas educativas y al mejoramiento de los comportamientos como una posibilidad de aprendizajes motivantes (Marzano y Pickering, 2005).

\section{La motivación: un camino a construir desde las particularidades personales}

Los escenarios cambiantes, el avance de las nuevas tecnologías, la masificación de la información y las necesidades de los estudiantes, pueden ser el punto de partida para establecer modificaciones en las estructuras curriculares, las cuales permitan visualizar una escuela que genere interés en los participantes y una renovación de contenidos acorde a los retos que impone una sociedad en continua transformación. Es claro que, la escuela tradicional estaba ligada a al costumbrismo, la repetición y la sanción, como mecanismos de motivación extrínseca, sin embargo, Gardner (2014) especifica que "Las recompensas proporcionadas por terceros son útiles, pero las actividades más importantes son las que ofrecen recompensas intrínsecas, basadas en los placeres personales que se van descubriendo a medida que se explora el mundo" (p.40). En este sentido, los estudiantes de la (LSB) plantean que hay diferentes asignaturas que les generan motivación y esta percepción está relacionada con la forma en que se presentan los contenidos, el carácter o el buen trato que tiene el maestro hacia ellos, la valoración del trabajo que se desarrolla durante las sesiones de clase, la gradualidad al abordar los temas complejos y la relación que tienen las temáticas con su aplicación a la vida personal (Piñeros, 2019).

Desde esta perspectiva, se hablaría de una motivación de carácter extrínseco y una motivación de carácter intrínseco. La motivación extrínseca estaría relacionada con aquellos factores externos que generan un estímulo positivo o negativo, con la intencionalidad de producir una emoción en los participantes y así, llegar al aprendizaje a través de la conexión social. Se considera que "el cerebro social cuenta con infinidad de circuitos, todos ellos concebidos para adaptarse a la mente de otra persona e interactuar con ella" (Goleman, 2012, p.73). Del mismo modo, el maestro como guía en los procesos de enseñanza, saber y aprendizaje puede encontrar en este tipo de motivación una herramienta que le permita propiciar la empatía del 
estudiante hacia los contenidos, la metodología utilizada por el educador, las posibilidades de aplicación de lo interiorizado y la necesidad de asistir continuamente a clases. Como lo expresa Goleman, (2012)

Eso significa que, básicamente influimos de forma constante en el estado cerebral de los demás. Según mi modelo de inteligencia emocional, la gestión de las relaciones quiere decir, en este nivel, que somos responsables de cómo determinamos los sentimientos de las personas con las que interactuamos, para bien o para mal. En ese sentido, la capacidad relacional tiene que ver con la gestión de los estados cerebrales de los demás. (p.75)

Por otro lado, tenemos la motivación intrínseca, determinada por las intencionalidades que llevan a la persona a satisfacer sus necesidades o deseos. Esta motivación está mediada por un "empeño genuino por aprender, por el solo placer de lograrlo y sin que medie premio o retribución alguna" (López, 2012, p.110). Desde esta perspectiva, los estudiantes de grado undécimo en la (LSB) expresan que la "asistencia al colegio es una posibilidad de aprendizaje, que permite mejorar mis condiciones a nivel personal desde el aspecto emocional, laboral, familiar y profesional" (Piñeros, 2019, p.145). Esta percepción de los jóvenes abre la posibilidad a los maestros de considerar una mayor participación de sus estudiantes en la formulación de los contenidos, en la revisión de los procesos y en la estructuración de la evaluación, como un factor que puede fomentar una escuela agradable y con pertinencia educativa, la cual considere sus motivaciones extrínsecas e intrínsecas desde el ámbito emocional considerando que:

Los resultados recientes de la investigación neurocientífica indican que las emociones son, en buena parte, responsables del desempeño cognitivo de los niños y también de los adultos. Por esta razón el factor emocional entendido como una variable educativa básica en la escuela y para el mejoramiento de la enseñanza, debe estar cada vez más presente en los proyectos curriculares. No obstante, lo anterior, la percepción de muchos educadores es que esta variable educativa no se reconoce como es debido, tal 
vez porque no se le ha dado la importancia y el valor que tiene en el éxito del funcionamiento cognitivo. (López, 2012, p.106)

Por lo tanto, el primer aporte que propone la investigación al campo educativo está direccionado hacia una inclusión del componente socioemocional dentro de las estructuras curriculares como una oportunidad para generar transformaciones pertinentes en las realidades personales de los jóvenes.

\section{Hacia el bien común: una perspectiva ética del acto educativo}

Evidenciar en la práctica una equidad en términos de aprendizaje, requiere considerar las ausencias que presentan los jóvenes y posibilitar desde la escuela una manera de abordar estas particularidades, para generar un proceso educativo útil a todos los participantes. Es claro que "El clima de violencia que se experimenta en determinadas comunidades tiene impactos muy negativos en niños, niñas y adolescentes" (CIDH, 2015, p.36). Como se puede observar desde el punto de vista de los estudiantes de la (LSB) las actitudes negativas de algunos compañeros de clase relacionadas con matoneo, irrespeto, falta de compromiso con las actividades y violencia escolar, son un factor que impide desarrollar aprendizajes y fomenta la desmotivación en la asistencia a clases ( (Piñeros, 2019). En este sentido las conductas violentas aprendidas en los entornos contextuales y que, son llevadas a los planteles educativos puede influir en las participación y permanencia de los estudiantes afectados tal como lo plantea la CIDH, (2015):

La violencia no solo impacta en la integridad física y psicológica del niño, sino que afecta su derecho a la salud, su desarrollo integral y tiene consecuencias en su derecho a la educación --ya sea porque la violencia se da en el ámbito escolar, como cuando se da en otro ámbito por incidir en la capacidad del niño de seguir normalmente el proceso educativo-. La violencia en el ámbito comunitario también puede influir en decisiones de sus cuidadores o del propio niño que restrinjan su libertad personal por temor a 
exponerse a riesgos; por ende, más derechos pueden verse afectados como el derecho al ocio, a la recreación y a la cultura, entre otros derechos. (p.64)

Desde esta perspectiva, la escuela, considerada como un escenario clave en la formación educativa y cultural de una sociedad, debe posibilitar espacios educativos que ayuden a delimitar las conductas que pueden ser abordadas dentro de la estructura curricular, como un aporte al mejoramiento del clima escolar, considerando que "las diferentes personas manifiestan diferentes grados de comportamiento ético o moral, dependiendo de su exposición a tales contingencias (Skinner, 1974, p.178)”. Así mismo, consolidar un ambiente educativo en el cual prolifere el respeto, la tolerancia a la diferencia, el bien colectivo y la conciencia social en la escuela, presupone un primer paso en el camino hacia la modificación es las conductas nocivas que afectan el clima escolar. En concordancia:

Las diferentes competencias de carácter emocional, social y ético deben ser promovidas desde los planes de estudio, las estructuras curriculares, los contenidos en cada asignatura y la filosofía institucional, considerando que los contextos vulnerables con problemáticas particulares requieren abordajes educativos frente a las situaciones que puedan intervenir en el crecimiento personal. (Piñeros, 2019, p.168)

Pensar en el bien común implica desligarse de la posición egocéntrica en la cual solo se aspira a satisfacer las necesidades personales, sin importar las consecuencias que se presenten por este tipo de conductas. Es notable que nuestro sistema educativo está pensado para responder a diferentes retos de forma individual y la cultura escolar privilegia a los niños que presentan mejores desempeños a nivel académico. Sin embargo, los docentes como investigadores en el ámbito pedagógico podemos propiciar nuevas modificaciones curriculares, que nos permitan proponer otras miradas integrales, considerando que el maestro es un modelo que seguir en la escuela y una guía en los diferentes patrones de comportamiento (Gardner, 2007). Así mismo "Como educadores debemos contribuir a que los jóvenes disciernan las inadecuaciones de sus creencias anteriores y construyan conceptos mejores y más verídicos” (Gardner, 2011, p.154). 
Pensar una escuela que brinde importancia al trabajo colectivo consciente, desde las primeras etapas educativas, implica decantar los contenidos, realizar acuerdos interdisciplinares, generar espacios de diálogo constructivo y privilegiar las relaciones interpersonales, teniendo en cuenta que "los compañeros de estudio revisten gran importancia ya que se consideran como un soporte emocional que permite nuevos aprendizajes y genera un mejor ambiente para asistir a la escuela" (Piñeros, 2019, p.176). Al respecto, Piaget, (1984) afirma que "La cooperación de niño con el adulto en la medida que es realizable y en la medida que se nos facilita a través de la colaboración de los niños entre sí, ¿no podría proporcionarnos la clave de la interiorización de las consignas de la autonomía de la conciencia moral?” (p.23). Es decir, estructurar bases sólidas a nivel ético desde los lineamientos curriculares, desde el abordaje disciplinar y desde el ejemplo del maestro son derroteros a seguir en un trabajo que privilegie el bien común, en una sociedad que pide constantemente modificación en los comportamientos de sus habitantes, desde una línea personalista en donde "la relación del yo al tú es el amor, mediante el cual mi persona se descentra en cierto modo y vive en la otra aun poseyéndose a sí misma y poseyendo su amor”(Mounier, 1974, p.223).

\section{Metodología}

La presente investigación se desarrolla desde un enfoque cualitativo, el cual "pretende acercarse al mundo de "ahí fuera" (no en entornos de investigación especializada como los laboratorios) y entender, describir y algunas veces explicar fenómenos sociales "desde el interior" de varias maneras diferentes" (Gibbs,2012,p.14), en esta investigación particularmente se buscaba interpretar las realidades que perciben los estudiantes de grado undécimo en la (LSB) en relación a las motivaciones intrínsecas y extrínsecas que guían su participación y asistencia a clases. Se realiza la investigación desde el presupuesto epistémico denominado interaccionismo simbólico, el cual

se basa en los más recientes análisis de tres sencillas premisas. La primera es que el ser humano orienta sus actos hacia las cosas en función de lo que estas significan para él. La segunda premisa es que el significado de estas cosas se deriva de, o surge como 
consecuencia de la interacción social, que cada cual mantiene con el prójimo. La tercera es que los significados se manipulan y modifican mediante un proceso interpretativo desarrollado por la persona al enfrentarse con las cosas que va hallando a su paso. (Blumer, 1982, p.2)

En esta misma línea, se busca indagar desde el significado que tiene para los estudiantes y docentes el acto educativo, pedagógico y didáctico mediado por las relaciones que se presentan entre el saber, la enseñanza y el aprendizaje en la localidad séptima de Bogotá, partiendo de la interacción que tiene el estudiante y el docente con su realidad, que es materializada en sus percepciones. Desde esta perspectiva, en una primera etapa se propone un recorrido teórico desde los diferentes postulados a nivel emocional, social y ético, considerando autores, como Goleman, Peter y Salovey, Gardner, Mounier, Aristóteles, Emmanuel Kant, Michael Domjan y Joan Carles Melich, entre otros. Se realiza una revisión en este campo de aproximadamente 120 textos de los cuales emergen dos categorías mencionadas anteriormente en el estado del arte. De la emergencia de estas categorías se propone un diseño metodológico basado en la teoría fundamentada, la cual es definida por Strauss \& Corbin, (2002) "como una teoría derivada de datos recopilados de manera sistemática y analizados por medio de un proceso de investigación. En este método, la recolección de datos, el análisis y la teoría que surgirá de ellos guardan estrecha relación entre sí” (p.21).

Como instrumentos para recoger la información se diseña un cuestionario (ver figura 2) el cual es evaluado por tres Doctores expertos en el campo de la investigación educativa, quienes realizan una valoración de cada una de las preguntas desde la pertinencia, redacción, relevancia y claridad, especificando las posibilidades de evaluación y las observaciones que pueden ser modificadas para llegar a un buen resultado a nivel de la interpretación de las respuestas. Posteriormente se selecciona la unidad de análisis la cual corresponde a un grado undécimo, el cual es encuestado de forma aleatoria en cada plantel educativo, según la disponibilidad que el directivo docente nos indica. Los Colegios evaluados se seleccionan con base en los siguientes criterios, población mayor a 3.000 participantes, zona de ubicación en 
la localidad y permiso por parte de los directivos docentes para hacer aplicación de los instrumentos. Estos planteles educativos son: Colegio Kimmy Pernía Domico (CKPD), Colegio Carlos Albán Holguín (CCAH), Colegio Leonardo Posada Pedraza (CLPP), Colegio Porfirio Barba Jacob (CPBJ), Colegio Ciudadela Educativa de Bosa (CCEB), Colegio Cedid San Pablo (CCSP) y Colegio Carlos Pizarro León (CCPLG). Después de la validación se aplica la encuesta (ver figura 2) y se realiza el proceso de transcripción de las respuestas de los estudiantes de vista de los estudiantes (ver figura 3).

Continuando con el proceso se codifican los términos de forma abierta y se brinda un concepto según los memos o palabras recurrentes, por cada pregunta (ver figura 4), luego se categorizan las respuestas por cada plantel educativo (ver figura 5). Sigue la fase de la categorización axial en donde se observan los términos recurrentes en cada respuesta y su correlación en los diferentes planteles educativos (ver figura 6). Cada pregunta sistematizada en todos los planteles se consolida como una subcategoría de análisis y se confronta con autores en la codificación teórica (ver figura 7). Es decir, de las respuestas de la pregunta uno a la pregunta seis forman la categoría Motivaciones para asistir a clases (MPAC), de las preguntas siete, ocho y nueve, emerge la categoría Buen Vivir (BV) y de la pregunta diez, once, doce y trece, emerge la categoría Pedagogía y Didáctica (PD). Cada categoría que emerge de las respuestas de los estudiantes, el punto de vista del investigador en confrontación con diferentes autores arroja una teoría sustantiva y la suma de cada teoría sustantiva nos brinda la teoría fundamentada. 
Figura 2. Encuesta abierta estudiantes (LSB)

\section{Encuesta validada para estudiantes.}

Nombre:

Grado:

Edad:

Colegio:

La encuesta presentada a continuación hace parte del proyecto de investigación: "Pedagogía de la biomotricidad: Orientaciones didácticas basadas en el buen vivir", desarrollado en el marco del Doctorado en Educación y Sociedad de la Universidad de la Salle; en este sentido el cuestionario tiene como objetivo: Identificar las principales motivaciones que llevan a los estudiantes de grado undécimo de la localidad séptima de Bogotá a asistir a la escuela, considerando sus percepciones sobre el buen vivir, sobre las áreas de conocimiento recibidas y sobre la importancia de la educación física. Las respuestas aportadas por los participantes únicamente se utilizarán con fines investigativos en el ámbito educativo.

1- ¿Cuál es su principal motivación para asistir al colegio?

2 ¿Cuáles aspectos no lo motivan para asistir al colegio?

3- ¿Cuáles son las asignaturas que le agradan? ¿Por qué?

4- ¿Cuáles son las asignaturas que le desagradan? ¿por qué?

5- ¿Hay algunos aspectos de la enseñanza de sus profesores que le parecen agradables? ¿Cuáles?

6- ¿Hay algunos aspectos en la enseñanza de sus profesores que se pueden mejorar? ¿Cuáles?

7- ¿Qué habilidades considera usted debe tener un estudiante de su colegio para ser feliz en la vida?

8- ¿Qué significa para usted una vida feliz?

9- ¿Son importantes para usted sus compañeros de estudio? ¿Por qué?

10- ¿Cuáles son las características ideales que debe tener un profesor?

11- ¿Qué aspectos considera que podrían facilitar el aprendizaje en las diferentes asignaturas?

12- ¿Qué características ideales debe tener un estudiante?

13- ¿Qué aspectos considera que pueden afectar positiva o negativamente el aprendizaje de los niños, niñas y jóvenes de su colegio? 
Figura 3. Transcripción de las respuestas de los estudiantes (LSB).

2- ¿Cuáles aspectos no lo motivan para asistir al colegio?

\begin{tabular}{|l|l|}
\hline & \multicolumn{1}{|c|}{ Respuestas Institución educativa distrital Carlos Albán Holguín. } \\
\hline 1 & La distancia \\
\hline 2 & Algunos profesores que se desvían del tema y casi no les entiendo \\
\hline 3 & Algunas clases y la actitud de algunos compañeros y profesores. \\
\hline 4 & Ninguno. \\
\hline 5 & $\begin{array}{l}\text { Las peleas o situaciones que se presentan en la salida y también la presencia de los } \\
\text { ñeros. }\end{array}$ \\
\hline 6 & A veces no alcanzo a hacer unos trabajos y algunos profesores. \\
\hline 7 & Ninguno. \\
\hline 8 & Ninguno. \\
\hline 9 & Ninguno. \\
\hline 10 & Cuando las materias son aburridas en un día determinado. \\
\hline 11 & La distancia del colegio a mi casa. \\
\hline 12 & La gran cantidad de ñeros tanto a la entrada al colegio como también dentro de la \\
institución, los baños permanecen oliendo a marihuana y los robos.
\end{tabular}


Figura 4. Codificación abierta.

\section{Pregunta 1 ¿Cuál es su principal motivación para asistir al colegio?}

Aprender más cosas, tener más capacidad de saber cosas nuevas, ser alguien el cual sepa mucho

Mi motivación es tener un conocimiento básico para poder ingresar a una universidad o al Sena, estudiar una carrera o técnico y ser una persona exitosa.

Pues poder venir a desarrollar un mejor camino para mi vida con buenos desempeños.

El aprender nuevas cosas cada día

Asisto para aprender nuevas cosas y para ser mejor como persona.

Mi principal motivación es estudiar, aprender, ampliar mi mente para ser una mejor persona,

Mi principal motivación para asistir al colegio es mejorar a nivel intelectual

Adquirir conocimiento necesario para mi vida.

Es aprender todos los días algo nuevo.

Es aprender

Aprender mucho para ser alguien en la vida

Aprender cosas nuevas, salir de la ignorancia, prepararme para la vida

Aprender cosas nuevas como convivir, las materias

Prepararme para cuando salga del colegio

Para aprender más, poder entender mejor las cosas que vemos cotidianamente

Tener más conocimiento sobre los que se aprende en cada asignatura

Poder obtener nuevos conocimientos, desarrollar nuevas habilidades, proyectarme mejor

para un futuro, superarme como persona, para obtener mis sueños y metas.

terminar mis estudios

Terminar el grado que estoy haciendo.

El diploma para poder conseguir trabajos.

para poderme graduar

Ganar el cartón para así se me abran oportunidades de trabajo.

Graduarme de once

Conseguir mi diploma para acceder a la educación superior.

Salir adelante

Conseguir un buen futuro

Conceptualización. Aprender cosas nuevas como herramienta para la vida, desde lo personal, laboral y profesional.| 
Figura 5. Categorización de la información según recurrencia

\section{COLEGIO CARLOS ALBÁN HOLGUÍN (CCAH)}

Pregunta 1 (CCAH): ¿Cuál es su principal motivación para asistir al colegio?

Objetivo (CCAH pl): identificar los factores extrínsecos e intrínsecos que motivan a los estudiantes de grado undécimo a asistir a la escuela.

\begin{tabular}{|l|c|c|c|}
\hline Respuestas recurrentes & Color & \multicolumn{1}{|c|}{ Estudiantes } & $\begin{array}{c}\text { Numero de } \\
\text { respuestas. }\end{array}$ \\
\hline $\begin{array}{l}\text { Aprender cosas nuevas como } \\
\text { herramienta para la vida, desde lo } \\
\text { personal, laboral y profesional. }\end{array}$ & $\mathrm{X}$ & $\begin{array}{l}1,2,3,4,5,6,9,10,12, \\
13,14,15,16,17,18,19, \\
21,22,24,25,26,27,28, \\
2930,31,32,33,34,37, \\
38 .\end{array}$ & 31 \\
\hline $\begin{array}{l}\text { Por mi familia como una forma de } \\
\text { retribuirle los beneficios que me han } \\
\text { brindado, asegurar su bienestar futuro } \\
\text { una posibilidad de hacerlos sentir } \\
\text { orgullosos. }\end{array}$ & $\mathrm{X}$ & $\begin{array}{l}8,12,13,15,16,20,23, \\
28,33,35,36,37,38\end{array}$ & 13 \\
\hline $\begin{array}{l}\text { El compartir con diferentes compañeros } \\
\text { y compartir con mis amigos. }\end{array}$ & $\mathrm{X}$ & $10,13,17,19,21,14,25$ & 7 \\
\hline $\begin{array}{l}\text { La motivación que representa una buena } \\
\text { actitud por parte de los maestros. }\end{array}$ & $\mathrm{X}$ & 11 & 1 \\
\hline
\end{tabular}

Comentario (CCAH pl): Los estudiantes del grado undécimo del (CCAH) manifiestan que una de las principales motivaciones para asistir a la escuela es el aprendizaje de nuevos conocimientos, ya que puede posibilitarle unas mejores condiciones de vida a nivel laboral, profesional, social y personal. Del mismo modo la familia tiene para los estudiantes un rol protagónico, considerando que a través del estudio pueden darle una mejor calidad de vida. Por último los compañeros de estudio representan para los jóvenes una compañia y una posibilidad de aprendizaje que estimula la asistencia y participación activa en los escenarios escolares. 
Figura 6. Codificación axial

Memos o palabras claves:

Pregunta 1: ¿Cuál es su principal motivación para asistir al colegio?

Objetivo (p1): identificar los factores extrínsecos e intrínsecos que motivan a los estudiantes de grado undécimo a asistir a la escuela.

Comentario por plantel educativo pregunta 1

Comentario (CCAH p1): Los estudiantes del grado undécimo del (CCAH) manifiestan que una de las principales motivaciones para asistir a la escuela es el aprendizaje de nuevos conocimientos, ya que puede posibilitarle unas mejores condiciones de vida a nivel laboral, profesional, social y personal. Del mismo modo la familia tiene para los estudiantes un rol protagónico, considerando que a través del estudio pueden darle una mejor calidad de vida. Por último los compañeros de estudio representan para los jóvenes una compañía y una posibilidad de aprendizaje que estimula la asistencia y participación activa en los escenarios escolares.

Comentario (CCEB p1): La gran mayoria de estudiantes en esta pregunta asisten al colegio con la motivación de adquirir herramientas para la vida, que les permitan surgir a nivel personal, laboral y profesional. El segundo grupo referencia a la familia como una motivación para asistir al colegio, considerando que al acceder a la educación se puede mejorar la calidad de vida de la familia y al ser bueno en los procesos académicos se puede estimular el orgullo en ellos.

Comentario (CCPLG p1): Los estudiantes de grado undécimo del (CCPLG) expresan que su principal motivación para asistir al colegio está relacionada con los deseos de aprender diferentes cosas que les sirvan como una herramienta que les permita el crecimiento a nivel personal, profesional y laboral. En esta misma línea algunos estudiantes asisten al colegio motivados por socializar con sus compañeros y con el deseo de hacer sentir orgullosos a sus familias y de alguna manera retribuirles económica y moralmente su acompañamiento en este proceso. 
Figura 7. Codificación teórica

\begin{tabular}{|c|c|c|c|}
\hline & Subcategorias & Codificación teórica. & Teoría sustantiva \\
\hline $\begin{array}{l}\text { Categoría } 1 \\
\text { Motivaciones } \\
\text { Para Asistir } \\
\text { a Clase } \\
\text { (MPAC) }\end{array}$ & 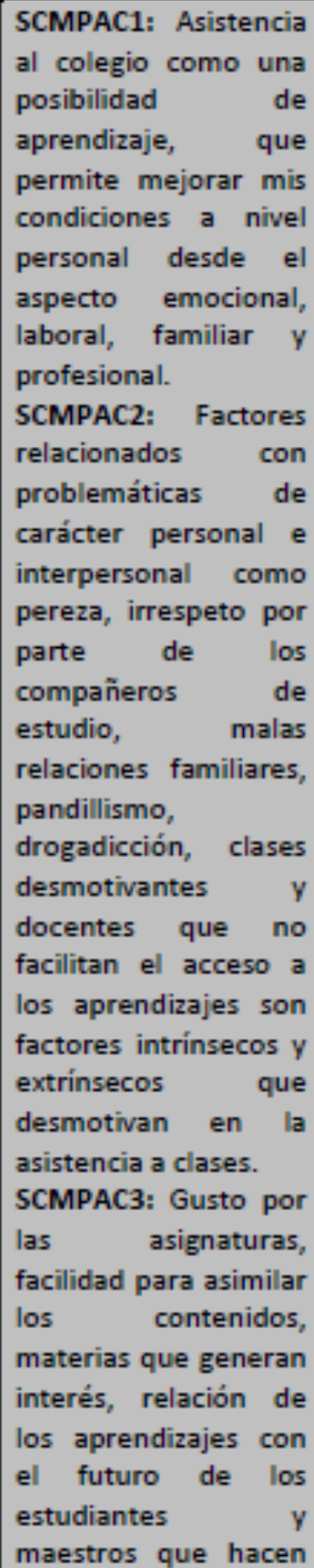 & $\begin{array}{l}\text { "En consecuencia, la educación } \\
\text { debe ponerse como meta el } \\
\text { equilibrio de su intervención en } \\
\text { cuanto a los aspectos cognitivos } \\
\text { y los emocionales, con la } \\
\text { finalidad de lograr el desarrollo } \\
\text { integral del ser humano. Este } \\
\text { desarrollo comprende también } \\
\text { la adquisición de una identidady } \\
\text { autoconocimiento sólidos que } \\
\text { permitan a los alumnos y } \\
\text { alumnas enfrentarse de forma } \\
\text { autónoma, responsable, } \\
\text { reflexiva y crítica a las diversas } \\
\text { situaciones sociales que impone } \\
\text { la vida cotidiana"(Santos \& Ruiz, } \\
\text { 2016, p.319). } \\
\text { "Los adolescentes con baja IE } \\
\text { poseen peores habilidades } \\
\text { interpersonales y sociales, lo que } \\
\text { puede generar el desarrollo de } \\
\text { conductas de riesgo. La } \\
\text { investigación indica que los } \\
\text { adolescentes con una menor IE } \\
\text { tienen más posibilidades de } \\
\text { consumir drogas como tabaco y } \\
\text { alcohol, o drogas ilegales como } \\
\text { cannabis o cocaína. Los } \\
\text { adolescentes con una mayor } \\
\text { habilidad para manejar sus } \\
\text { emociones son capaces de } \\
\text { afrontarlas de forma adaptativa } \\
\text { en su vida cotidiana, teniendo } \\
\text { como consecuencia un mejor } \\
\text { ajuste psicológico, una menor } \\
\text { búsqueda de sensaciones y un } \\
\text { menor consumo de drogas" } \\
\text { (Pacheco \& Berrocal, } 2013, \\
\text { p.36). } \text { "Otros beneficios de la }\end{array}$ & 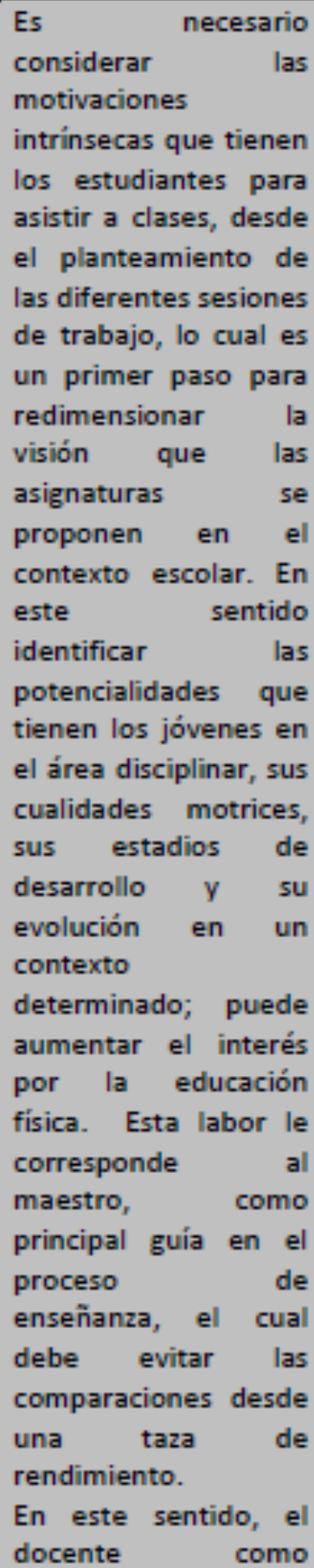 \\
\hline
\end{tabular}




\section{Resultados}

Considerando el objetivo propuesto en la investigación "Conocer las principales motivaciones que llevan a los estudiantes de grado undécimo de la Localidad Séptima de Bogotá (LSB) a asistir a la escuela". Se exponen los resultados con base a las respuestas que brindaron los estudiantes al cuestionario propuesto.

\section{Pregunta 1 (P1): ¿Cuál es su principal motivación para asistir al colegio?}

Figura 8. Respuestas pregunta 1

\begin{tabular}{|l|c|c|c|c|}
\hline \multicolumn{1}{|c|}{$\begin{array}{c}\text { Respuestas } \\
\text { recurrentes }\end{array}$} & Color & $\begin{array}{c}\text { Numero de respuestas } \\
\text { por colegio }\end{array}$ & Total & Porcentaje \\
\hline $\begin{array}{l}\text { Aprender cosas } \\
\text { nuevas como } \\
\text { herramienta para la } \\
\text { vida, desde lo } \\
\text { personal, laboral y } \\
\text { profesional. }\end{array}$ & $\begin{array}{c}\text { CCPLG24,CAH31,CCS } \\
\text { P39,CCEB32,CKPD22, } \\
\text { CPBJ26,CLPP31 }\end{array}$ & 205 & $72.9 \%$ \\
\hline $\begin{array}{l}\text { Por mi familia como } \\
\text { una forma de } \\
\text { retribuirle los } \\
\text { beneficios que me } \\
\text { han brimdado, } \\
\text { asegurar subienestar } \\
\text { futuro una } \\
\text { posibilidad de } \\
\text { hacerlos sentir } \\
\text { orgullosos. }\end{array}$ & & $5,13,6,11,2,4,2$ & 43 & $15.3 \%$ \\
\hline $\begin{array}{l}\text { El compartir con } \\
\text { diferentes } \\
\text { compañeros y } \\
\text { compartir con mis } \\
\text { amigos. }\end{array}$ & & & & \\
\hline
\end{tabular}




\section{Descripción respuestas a la pregunta 1}

La respuesta de los estudiantes con relación a esta pregunta evidencia que la principal motivación para la asistencia a los planteles educativos se relaciona con el deseo de aprender nuevos conocimientos que le permitan desenvolverse de forma adecuada en el ámbito profesional, laboral y personal. Los estudiantes en esta localidad consideran que el estudio puede ser una opción para mejorar su calidad de vida y así, devolverles a sus padres algo de lo que ellos han invertido en su formación. Por otro lado, la asistencia a clases en gran medida está ligada al compartir con sus compañeros y docentes que son de su agrado, lo cual representa una de sus mayores motivaciones en contexto escolar. Desde esta perspectiva, considerar las motivaciones intrínsecas y extrínsecas que llevan a los jóvenes a asistir al colegio nos puede llevar al planteamiento de nuevas posibilidades de evaluación en el aula de clases que consideren los estadios neurobiológicos de aprendizaje y la predisposición con la cual un joven llega al lugar donde aprende. En este sentido, es indispensable que la escuela realice una caracterización socio-demográfica que permita identificar aquellos aspectos que pueden incidir en la desmotivación de los estudiantes y así plantear estrategias en colectivo para moddificar las situaciones negativas. 
Pregunta 2 (P2): ¿Cuáles aspectos no lo motivan para asistir al colegio?

Figura 9. Respuestas pregunta 2

\begin{tabular}{|c|c|c|c|c|}
\hline Respuestas recurrentes & Color & $\begin{array}{c}\text { Numero de } \\
\text { respuestas por } \\
\text { colegio }\end{array}$ & Total & Porcentaje \\
\hline Ninguno. & $\mathrm{X}$ & $5,2,10,2,2,6,0$ & 27 & $10,03 \%$ \\
\hline $\begin{array}{l}\text { La distancia de la casa al } \\
\text { colegio }\end{array}$ & $\mathrm{X}$ & $4,6,2,1,1,0,0$ & 14 & $5.2 \%$ \\
\hline $\begin{array}{l}\text { Los profesores en ocasiones } \\
\text { no se hacen entender bien o } \\
\text { tienen algunos defectos a } \\
\text { nivel interpersonal que } \\
\text { desmotivan }\end{array}$ & $\mathrm{X}$ & $6,5,11,7,3,7,8$ & 47 & $17.4 \%$ \\
\hline $\begin{array}{l}\text { Las materias aburridas o que } \\
\text { representan dificultad. }\end{array}$ & $\mathrm{X}$ & $2,8,16,14,5,8,11$ & 64 & $23.7 \%$ \\
\hline $\begin{array}{l}\text { Situaciones de imseguridad, } \\
\text { rĩas y personas agresivas, } \\
\text { dentro y fuera del colegio. }\end{array}$ & $\mathrm{X}$ & $6,7,4,6,6,9,5$, & 43 & $15.9 \%$ \\
\hline $\begin{array}{l}\text { Problemas personales y } \\
\text { familiares que afectan mi } \\
\text { estudio. }\end{array}$ & $\mathrm{X}$ & $7,10,5,14,14,3,15$ & 68 & $25.2 \%$ \\
\hline $\begin{array}{l}\text { Largas jomadas y Disgusto } \\
\text { por la alimentacion. }\end{array}$ & $\mathrm{X}$ & $0,0,0,0,0,4,0$ & 4 & $1.4 \%$ \\
\hline $\begin{array}{l}\text { Baja calidad en la educación } \\
\text { mang }\end{array}$ & $\mathrm{X}$ & $0,0,2,0,0,0,0$ & 2 & $0.7 \%$ \\
\hline
\end{tabular}




\section{Descripción respuestas a la pregunta 2}

En relación con esta pregunta los estudiantes de la (LSB) exponen que en gran parte su desmotivación para la asistencia a clases se relaciona con algunas problemáticas de carácter familiar, algunas áreas de conocimiento que son muy difíciles o con contenidos descontextualizados. En la misma línea, encuentran una ausencia por parte de los docentes para hacerse comprender, o poca empatía a nivel socioemocional a la hora de plantear su proceso de enseñanza. Por último, las riñas, las pandillas, las personas agresivas dentro y fuera de la institución y la distancia al colegio son otros aspectos que también disminuyen la motivación para asistir al colegio.

Es notable que los estudiantes en los planteles educativos distritales están en continua lucha contra diferentes factores que inciden en la motivación de los jóvenes al asistir al aula de clases. Sin embargo, la escuela tiene la obligación de comprender que anexo al rendimiento académico en estos contextos poblacionales, se deben considerar las ausencias familiares materializadas en abandono, el maltrato infantil producto de ausencia de liderazgo y el escaso interés por parte de las familias en los procesos educativos. Por otro lado, como lo expresan los estudiantes los docentes deben irradiar empatía en sus prácticas de enseñanza, lo cual implica, proponer desde la planeación ajustes necesarios para lograr mayores niveles de motivación, incremento en los aprendizajes y participación por parte de los estudiantes. En relación con los contextos complejos, la tarea parte de un trabajo interdisciplinar entre la escuela, las autoridades competentes, las familias y los espacios de aprovechamiento del tiempo libre que se puedan proponer desde la política pública, ya que, la realidad contextual del niño determina sus posibilidades éxito en relación con el acto educativo. (CIDH, 2015) 
Pregunta 3 (P3) ¿Cuáles son las asignaturas que le agradan? ¿Por qué?

Figura 10. Respuestas pregunta 3

\begin{tabular}{|l|c|c|c|c|}
\hline \multicolumn{1}{|c|}{ Respuestas recurrentes } & Color & $\begin{array}{c}\text { Numero de } \\
\text { respuestas por } \\
\text { colegio }\end{array}$ & Total & Porcentaje \\
\hline $\begin{array}{l}\text { El maestro explica de forma } \\
\text { agradable y entendible. }\end{array}$ & $\mathrm{X}$ & $0,8,4,3,1,3,5$ & 24 & $9.1 \%$ \\
\hline $\begin{array}{l}\text { Las materias se relacionan con } \\
\text { lo que quiero estudiar y son } \\
\text { útiles para mi futuro. }\end{array}$ & $\mathrm{X}$ & $4,7,6,3,5,2,4$ & 31 & $11.7 \%$ \\
\hline $\begin{array}{l}\text { Porque aprendo y le encuentro } \\
\text { aplicación a lo aprendido en mi } \\
\text { realidad. }\end{array}$ & $\mathrm{X}$ & $2,6,9,1,7,4,20$ & 49 & $18.6 \%$ \\
\hline $\begin{array}{l}\text { Las clases me apasionan, tienen } \\
\text { contenidos que me gustan y se } \\
\text { me facilita comprender }\end{array}$ & $\mathrm{X}$ & $17,26,29,32,20$, & 159 & $60.4 \%$ \\
\hline
\end{tabular}

\section{Descripción respuestas a la pregunta 3}

Los estudiantes caracterizan las asignaturas que les llaman la atención por el apasionamiento que les producen los temas desarrollados y su posibilidad de comprender estos temas. Es notable que los resultados en las distintas pruebas estandarizadas evidencian que los estudiantes en los colegios públicos de Bogotá no obtienen niveles superiores en diferentes componentes de las asignaturas evaluadas. Esto indicaría que a diferentes contenidos que se exponen en la escuela el estudiante puede no encontrarle un sentido y utilidad a su realidad particular de aplicación (Gardner, 2012). Lo cual nos llevaría a pensar que es indipensable 
desde la planeación generar contenidos que se relacionen con competencias escenciales para la vida cotidiana y que estimulen los aspectos motivacionales de los estudiantes hacia los nuevos aprendizajes. Del mismo modo, el encontrar un sentido a los trabajos desarrollados y una aplicación de lo aprendido a la realidad es un factor que aumenta el agrado por las asignaturas. Por último, los estudiantes plantean que la forma en que el docente expone los aprendizajes desde su quehacer pedagógico incide en el apasionamiento por las diferentes asignaturas. Este hallazgo nos invita a encontrarle un sentido a las apuestas metodológicas y didácticas que estimulan la participación de los jóvenes, considerando durante la elaboración de las unidades de trabajo, de la selección de los contenidos y de los procesos de retroalimentación, el punto de vista del educando y sus aportes a la construcción de las nuevas unidades de aprendizaje.

\section{Pregunta 4 (P4): ¿Cuáles son las asignaturas que le desagradan? ¿Por qué?}

Figura 11. Respuestas pregunta 4

\begin{tabular}{|l|c|c|c|c|}
\hline \multicolumn{1}{|c|}{ Respuestas recurrentes } & Color & $\begin{array}{c}\text { Numero de } \\
\text { respuestas } \\
\text { por colegio }\end{array}$ & Total & Porcentaje \\
\hline $\begin{array}{l}\text { Los profesores no tienen adecuada } \\
\text { metodología para explicar y algunas } \\
\text { actitudes de su personalidad no } \\
\text { facilitan el aprendizaje. }\end{array}$ & $\mathrm{X}$ & $6,18,6,2,4,6,5$ & 47 & $18.9 \%$ \\
\hline $\begin{array}{l}\text { No me agradan esas clases y no les } \\
\text { encuentro sentido. }\end{array}$ & $\mathrm{X}$ & $11,13,12,12,10$ & 88 & $35.4 \%$ \\
\hline $\begin{array}{l}\text { Se me dificulta entenderlas y la } \\
\text { ausencia de comprensión es estresante. }\end{array}$ & $\mathrm{X}$ & $9,16,21,28,15$, & 113 & $45.5 \%$ \\
\hline
\end{tabular}




\section{Descripción respuestas a la pregunta 4}

Los estudiantes en la (LSB) manifiestan que las materias que son complejas de entender disparan sus mecanismos del stress. De igual manera las asignaturas que no representan una ganancia en relación con la vida de los estudiantes, la ausencia de una adecuada metodología por parte de algunos maestros y las pocas herramientas de carácter interpersonal del líder del proceso son factores que disminuyen el gusto por algunas áreas disciplinares. Esta reflexión nos invita a la aplicación de una norma elemental del constructivismo la cual indica que es indispensable considerar los aprendizajes previos de los jóvenes, ya que es recurrente seguir una guía metodológica, como son los lineamientos curriculares dejando de lado la evaluación o diagnóstico que nos permite tener información "in situ" de la realidad de la comprensión de los estudiantes.

\section{Pregunta 5 (P5): ¿Hay algunos aspectos de la enseñanza de sus profesores que le parecen agradables? ¿Cuáles?}

Figura 12. Respuestas pregunta 5

\begin{tabular}{|l|c|c|c|c|}
\hline \multicolumn{1}{|c|}{ Respuestas recurrentes } & Color & $\begin{array}{c}\text { Numero de } \\
\text { respuestas por } \\
\text { colegio }\end{array}$ & Total & Porcentaje \\
\hline $\begin{array}{l}\text { La forma de enseñar, la preparación } \\
\text { académica, hacerse entender y las } \\
\text { buenas explicaciones. }\end{array}$ & $\mathrm{X}$ & $\begin{array}{c}14,18,18,19,14, \\
19,29\end{array}$ & 131 & $50 \%$ \\
\hline $\begin{array}{l}\text { Cualidades emocionales, sociales y } \\
\text { éticas del docente que permiten } \\
\text { generar un clima educativo y } \\
\text { formativo agradable. }\end{array}$ & $\mathrm{X}$ & $9,20,13,21,10,1$ & 99 & $37.7 \%$ \\
\hline $\begin{array}{l}\text { Los recursos metodológicos } \\
\text { utilizados por el maestro para facilitar } \\
\text { el aprendizaje y las clases que } \\
\text { rompen con la rutina. }\end{array}$ & $\mathrm{X}$ & $5,8,8,3,6,2,0$ & 32 & $12.2 \%$ \\
\hline
\end{tabular}




\section{Descripción respuestas a la pregunta 5}

En la (LSB) los estudiantes expresan que un docente preparado, que sabe explicar correctamente, que presenta empatía en relación con sus dificultades para el aprendizaje y que utiliza adecuados recursos pedagógicos y didácticos son necesarios en una enseñanza agradable. Básicamente el docente como un mediador entre la enseñanza, el saber y los aprendizajes está llamado a capacitarse continuamente, considerando que la evolución de las sociedades implica transformar la enseñanza en relación con los nuevos saberes que emergen en una sociedad globalizada. Por otro lado, las nuevas perspectivas que tienen los jóvenes en relación con sus necesidades de conocimiento y reconocimiento invitan a los educadores a fortalecer las competencias socioemocionales como un requisito indispensable para un clima escolar adecuado, unos niveles de motivación en los educandos altos y unas mayores posibilidades de éxito a nivel educativo. 
Pregunta 6 (P6): ¿Hay algunos aspectos en la enseñanza de sus profesores que se pueden mejorar? ¿Cuáles?

Figura 13. Respuestas pregunta 6

\begin{tabular}{|c|c|c|c|c|}
\hline $\begin{array}{l}\text { Respuestas } \\
\text { recurrentes }\end{array}$ & Color & $\begin{array}{c}\text { Numero de respuestas } \\
\text { por colegio }\end{array}$ & Total & Porcentaje \\
\hline $\begin{array}{l}\text { Los estudiantes } \\
\text { recomiendan cambiar } \\
\text { los métodos de } \\
\text { enseñanza y generar } \\
\text { mejores explicaciones } \\
\text { que permitan el } \\
\text { aprendizaje. Ya que las } \\
\text { explicaciones poco } \\
\text { entendibles no } \\
\text { permiten avanzar. }\end{array}$ & $\mathrm{X}$ & $14,21,20,22,19,17,19$ & 132 & $52.5 \%$ \\
\hline $\begin{array}{l}\text { Los estudiantes } \\
\text { consideran que los } \\
\text { maestros deben tener } \\
\text { más paciencia al } \\
\text { enseñar, un inmenso } \\
\text { respeto por las } \\
\text { diferencias en el } \\
\text { aprendizaje de sus } \\
\text { estudiantes y mayor } \\
\text { vocación. }\end{array}$ & $\mathrm{X}$ & $9,17,19,21,5,10,11$ & 92 & $36.6 \%$ \\
\hline $\begin{array}{l}\text { Ninguna los maestros } \\
\text { son comprometidos. }\end{array}$ & $\mathrm{X}$ & $0,0,5,0,5,13,4$ & 27 & $10.7 \%$ \\
\hline
\end{tabular}




\section{Descripción respuestas a la pregunta 6}

Desde la percepción de los estudiantes de grado undécimo en la (LSB) se sugiere una modificación en los métodos de enseñanza por parte de los maestros, con el objetivo de posibilitar mayores comprensiones. Esto implica, asumir que todos los días emergen nuevas maneras de enseñar y mediar en el aprendizaje ligado a procesos cerebrales que cada vez, la neurociencia cognitiva está detallando con mayor rigurosidad. En este sentido, es necesario considerar las diferencias que tienen los estudiantes al aproximarse a los saberes, valorar estas diferencias y profesar respeto a los educandos, a pesar de que no se logren los objetivos de aprendizaje que el docente plantea. Por otro lado, es evidente que los estudiantes perciben el compromiso que manifiesta su docente, desde sus apuestas didácticas y las actitudes que emanan en cada sesión de trabajo, lo cual invita a los maestros a preparar con rigurosidad sus

planteamientos y a valorar el esfuerzo del estudiante en cada apuesta metodológica y didáctica. 
Pregunta 7 (P7): ¿Qué habilidades considera usted debe tener un estudiante de su colegio para ser feliz en la vida?

Figura 14. Respuestas pregunta 7

\begin{tabular}{|c|c|c|c|c|}
\hline $\begin{array}{l}\text { Respuestas } \\
\text { recurrentes }\end{array}$ & Color & $\begin{array}{c}\text { Numero de } \\
\text { respuestas por } \\
\text { colegio }\end{array}$ & Total & Porcentaje \\
\hline $\begin{array}{l}\text { Los estudiantes en este } \\
\text { aspecto relacionan } \\
\text { competencias de } \\
\text { carácter emocional y } \\
\text { fundamentan los } \\
\text { aspectos éticos y la } \\
\text { formación en valores } \\
\text { como habilidades } \\
\text { relevantes para ser feliz } \\
\text { en la vida. }\end{array}$ & $\mathrm{X}$ & $\begin{array}{c}11,35,26,27,21,25,2 \\
9\end{array}$ & 174 & $66.41 \%$ \\
\hline $\begin{array}{l}\text { Competencias de } \\
\text { carácter académico. }\end{array}$ & $\mathrm{X}$ & $4,9,12,3,6,4,2$ & 40 & $15.26 \%$ \\
\hline $\begin{array}{l}\text { Habilidades meta } \\
\text { cognitivas o deseos de } \\
\text { aprender. }\end{array}$ & $\mathrm{X}$ & $0,4,8,5,0,0,0$ & 17 & $6.48 \%$ \\
\hline $\begin{array}{l}\text { Idontificar los aspoctos } \\
\text { en los cuales se tienen } \\
\text { habilidades para } \\
\text { posibilitar metas en la } \\
\text { vida }\end{array}$ & $\mathrm{x}$ & $4,0,3,4,3,4,5$ & 23 & $8.77 \%$ \\
\hline $\begin{array}{l}\text { Habilidad para } \\
\text { solucionar problemas. }\end{array}$ & $\mathrm{X}$ & $0,0,4,0,0,0,2$ & 6 & $2.29 \%$ \\
\hline Vida sana & $\mathrm{X}$ & $0,2,0,0,0,0,0$ & 2 & $0.7 \%$ \\
\hline
\end{tabular}




\section{Descripción respuestas a la pregunta 7}

Los estudiantes en la (LSB) manifiestan que un estudiante comprometido, disciplinado, con perseverancia y buenas herramientas emocionales puede acceder fácilmente a la felicidad. Es notable que diferentes investigadores como (Kandel, Schwartz, \& Jessel, 1997) y (Mora, 2013), especifican que los aspectos socio emocionales de la persona tienen una gran influencia en las posibilidades de éxito,las actitudes frente a la vida, las posibilidades de aprendizaje y los desarrollos cognitivos de los individuos. Por esta razón la escuela debe generar un apartado en cada unidad didáctica o planteamiento metodológico que se direccione a potenciar estos aspectos de la persona que aprende. Ya que las propuestas tradicionales en la educación han privilegiado lo componentes académicos del currículo, dejando de lado otros saberes expresados por los estudiantes en la investigación. Por otra parte, las competencias relacionadas con el aspecto académico, los procesos metacognitivos y la capacidad de reflexionar sobre los elementos relevantes en la vida, son componentes descritos por los estudiantes como necesarios en la aproximación a una visión de futuro a largo plazo. 
Pregunta 8 (P8): ¿Qué significa para usted una vida feliz?

Figura 15. Respuestas pregunta 8

\begin{tabular}{|c|c|c|c|c|}
\hline $\begin{array}{l}\text { Respuestas } \\
\text { recurrentes }\end{array}$ & Color & $\begin{array}{c}\text { Numero de } \\
\text { respuestas por } \\
\text { colegio }\end{array}$ & Total & Porcentaje \\
\hline $\begin{array}{l}\text { La vida feliz sa } \\
\text { relaciona con el acceso } \\
\text { mejores posibilidades } \\
\text { de vida en relación con } \\
\text { factores individuales, } \\
\text { como estar bien } \\
\text { consigo mismo, } \\
\text { estudiando, con una } \\
\text { buena profesión y } \\
\text { haciendo en la vida lo } \\
\text { que reslmente les } \\
\text { gusta }\end{array}$ & $\bar{X}$ & $\begin{array}{c}21,14,33,24,24,28,2 \\
7\end{array}$ & 171 & $55.33 \%$ \\
\hline $\begin{array}{l}\text { La vida feliz se } \\
\text { relaciona con las } \\
\text { relaciones } \\
\text { interpersonales, el } \\
\text { apoyo familiar, los } \\
\text { beneficios en colectivo } \\
\text { y un apoyo espiritual. }\end{array}$ & $\bar{X}$ & $\begin{array}{c}12,25,13,19,11,17,1 \\
4\end{array}$ & 111 & $35.92 \%$ \\
\hline $\begin{array}{l}\text { La vida feliz se } \\
\text { relaciona con algunos } \\
\text { elementos de carácter } \\
\text { material como dinero, } \\
\text { casa, mejor posición } \\
\text { económica. }\end{array}$ & $\bar{x}$ & $3,7,1,7,2,3,4$ & 27 & $8.73 \%$ \\
\hline
\end{tabular}


Descripción respuestas a la pregunta 8: Una vida feliz para los estudiantes en la (LSB) se relaciona con la posibilidad de estar bien internamente, con un buen trabajo y estudiando una carrera que realmente les apasione. Según las respuestas de los estudiantes de la (LSB) el objetivo primordial de asistir a clases es modificar sus posibilidades para insertarse de forma exitosa en la sociedad. Sin embargo, la escuela en ocasiones brinda una serie de contenidos que están desarticulados con el ámbito laboral, profesional o personal. Por esto, es necesario que la escuela genere convenios con las diferentes entidades técnicas, tecnológicas o universitarias, para fomentar unos escenarios reales de aplicación del conocimiento a entornos que le faciliten al estudiante aplicar sus aprendizajes. Por otro lado, el ámbito familiar, los amigos y las adecuadas relaciones personales son aspectos que los estudiantes consideran necesarios en sus perspectivas de vida ideal. En este sentido, la escuela debe preocuparse por la identificación de la realidad particular del estudiante, para generar transformaciones positivas en estos aspectos desde las diferentes competencias que se proponen en el currículo escolar. 


\section{Pregunta 9 (P9): ¿Son importantes para usted sus compañeros de estudio? ¿Por qué?}

Figura 16. Respuestas pregunta 9

\begin{tabular}{|l|c|c|c|c|}
\hline \multicolumn{1}{|c|}{ Respuestas recurrentes } & Color & $\begin{array}{c}\text { Numero de } \\
\text { respuestas por } \\
\text { colegio }\end{array}$ & Total & Porcentaje \\
\hline $\begin{array}{l}\text { Como un apoyo emocional que } \\
\text { pemite vivenciar la escuela, } \\
\text { compartir diferentes escenarios } \\
\text { y recibir sustento en momentos } \\
\text { dificiles. }\end{array}$ & $\mathrm{X}$ & $20,25,20,30,19$, & 153 & $60.23 \%$ \\
\hline $\begin{array}{l}\text { Como una fuente de } \\
\text { comprension que me pemite }\end{array}$ & $\mathrm{X}$ & $3,14,10,5,12,11,22$ & 61 & $24.01 \%$ \\
aprender y mejorar mis \\
posibilidades futuras.
\end{tabular}

Descripción respuestas a la pregunta 9: Los estudiantes en la (LSB) expresan que los compañeros de estudio son indispensables como apoyo en situaciones difíciles, además de hacer la escuela agradable gracias a su presencia. Es notable en las aulas de clase que la motivación de los estudiantes está relacionada con las interacciones a nivel personal, que se consolidan en la cotidianidad de la escuela. Sin embargo, la propuesta pedagógica tradicional, exalta la individualidad, la competitividad y el antropocentrismo. Por lo cual, se hace necesario desde las primeras etapas formativas fomentar el trabajo en equipo, el trabajo colaborativo y la interdependencia positiva, como elementos generadores de aprendizajes 
significativos a través de la interacción. Esta metodología puede ser efectiva, disminuyendo la competitividad, planteando logros comunes y privilegiando los aprendizajes del colectivo.

\section{Pregunta 10 (P10): ¿Cuáles son las características ideales que debe tener un profesor?}

Figura 17. Respuestas pregunta 10

\begin{tabular}{|l|c|c|c|c|}
\hline \multicolumn{1}{|c|}{$\begin{array}{c}\text { Respuestas } \\
\text { recurrentes }\end{array}$} & Color & $\begin{array}{c}\text { Numero de } \\
\text { respuestas por } \\
\text { colegio }\end{array}$ & Total & Porcentaje \\
\hline $\begin{array}{l}\text { Características carácter } \\
\text { relacionadas con } \\
\text { algunas competencias } \\
\text { de permiten } \\
\text { interpersonal y ético, } \\
\text { que los } \\
\text { aproximar a la } \\
\text { estudiantes a la } \\
\text { comprensión. }\end{array}$ & & $19,29,31,33,21,27,24$ & 184 & $53.80 \%$ \\
\hline $\begin{array}{l}\text { Competencias } \\
\text { relacionadas con la } \\
\text { preocupación que debe } \\
\text { tener el maestro frente } \\
\text { al aprendizaje de sus } \\
\text { estudiantes y la } \\
\text { formación desde la } \\
\text { enseñanza. }\end{array}$ & & $13,28,25,17,9,13,20$ & 125 & $36.5 \%$ \\
\hline $\begin{array}{l}\text { Competencias } \\
\text { relacionadas con el } \\
\text { dominio intelectual de } \\
\text { la disciplina. }\end{array}$ & & & & \\
\hline
\end{tabular}

Descripción respuestas a la pregunta 10: Las características que describen los estudiantes sobre su profesor ideal en la (LSB) se relacionan con unas adecuadas competencias socioemocionales ligadas al aspecto ético-profesional. Así mismo, un docente que profese empatía hacia el aprendizaje de sus estudiantes y empeño por la formación continua en su asignatura. 
Considerando que en las instituciones educativas distritales se presentan diferentes dificultades contextuales que afectan las posibilidades de aprendizaje de los estudiantes, el educador debe fortalecer algunas competencias en los aspectos cognitivos, socioemocionales y ético-profesionales para asumir una postura de transformación social en la comunidad educativa de la que hace parte. Las voces de los estudiantes en la (LSB) reclaman un docente con alto sentido de respeto por su profesión, con altas competencias intelectuales, con adecuadas relaciones hacia los jóvenes y un compromiso significativo hacia la labor de educar.

\section{Pregunta 11 (P11): ¿Qué aspectos considera que podrían facilitar el aprendizaje en las diferentes asignaturas?}

Figura 18. Respuestas pregunta 11

\begin{tabular}{|l|c|c|c|c|}
\hline Respuestas recurrentes & Color & $\begin{array}{c}\text { Numero de } \\
\text { respuestas } \\
\text { por colegio }\end{array}$ & Total & Porcentaje \\
\hline $\begin{array}{l}\text { Clases más dinámicas, } \\
\text { lúdicasy didácticas, con } \\
\text { un proceso que permita } \\
\text { aprendery variedadenla } \\
\text { forma de abordar los } \\
\text { contenidos. }\end{array}$ & $\mathrm{X}$ & $\begin{array}{c}13,21,18,18,16 \\
, 23,23,\end{array}$ & 132 & $50.57 \%$ \\
\hline $\begin{array}{l}\text { Mejores recursos e } \\
\text { instrumentos para el } \\
\text { desarrollo de las clases. }\end{array}$ & $\mathrm{X}$ & $2,14,4,7,1,9,2$ & 39 & $14.94 \%$ \\
\hline $\begin{array}{l}\text { Mejor actitud, } \\
\text { disposición y claridad } \\
\text { porparte delosmaestros. }\end{array}$ & $\mathrm{X}$ & $8,6,15,8,5,4,12$ & 58 & 22.22 \\
\hline $\begin{array}{l}\text { Actitudy disposiciónpor } \\
\text { parte de los estudiantes. }\end{array}$ & $\mathrm{X}$ & $1,3,4,6,4,6,3$ & 27 & $10.34 \%$ \\
\hline $\begin{array}{l}\text { Que la educación } \\
\text { responda a los intereses } \\
\text { de cada persona y sus } \\
\text { particularidades. }\end{array}$ & $\mathrm{X}$ & $0,0,3,0,0,0,2$ & 5 & $1.91 \%$ \\
\hline
\end{tabular}




\section{Descripción respuestas a la pregunta 11}

El aprendizaje puede ser facilitado, según los estudiantes en la (LSB) a través del mejoramiento de las apuestas metodológicas y didácticas, presentando unos contenidos que sean llamativos y lúdicos, lo cuales inviten a participar activamente en la clase. En este cuestionamiento los estudiantes expresan que una mejor disposición por parte de los jóvenes, maestros y gestores de la política pública puede facilitar una educación con mayor calidad, mayor pertinencia y con capacidad e impacto, teniendo en cuenta que "Hoy en día, la educación puede considerarse el principal acelerador de nuestro cerebro. Su lugar privilegiado, que recuerda por qué debe situarse entre los primeros puestos de las inversiones del Estado, se justifica fácilmente: sin ella, los circuitos corticales serían diamantes en bruto" (Dehaene, 2019, p.22). Desde esta perspectiva, urgen transformaciones integrales a los procesos educativos desde una perspectiva humanista, que involucre a estudiantes, docentes, padres de familia, Sociedad y política pública.

\section{Pregunta (P12): ¿Qué características ideales debe tener un estudiante?}

Figura 19. Respuestas pregunta 12

\begin{tabular}{|c|c|c|c|c|}
\hline Respuestas recurrentes & Color & $\begin{array}{l}\text { Numero de } \\
\text { respuestas por } \\
\text { colegio }\end{array}$ & Total & Porcentaje \\
\hline $\begin{array}{l}\text { Actitudes y } \\
\text { comportamientos de } \\
\text { carácter personal que } \\
\text { posibilitanla aceptación } \\
\text { en la sociedad, } \\
\text { delimitados en valores y } \\
\text { herramientas } \\
\text { emocionales. }\end{array}$ & $\mathrm{X}$ & $\begin{array}{c}23,38,35,32,23, \\
28,33\end{array}$ & 212 & $80.30 \%$ \\
\hline $\begin{array}{l}\text { Inteligencia a nivel } \\
\text { académico }\end{array}$ & $\mathrm{X}$ & $1,7,2,3,2,4,1$ & 20 & $7.57 \%$ \\
\hline $\begin{array}{l}\text { Amor y pasión por el } \\
\text { estudio y el aprendizaje. }\end{array}$ & $\mathbf{x}$ & $4,5,8,6,6,3,0$ & 32 & $12.12 \%$ \\
\hline
\end{tabular}




\section{Descripción respuestas a la pregunta 12}

En este aspecto los estudiantes de grado undécimo coinciden en que los valores y las herramientas socioemocionales son características de un buen estudiante. Hacen énfasis en el apasionamiento por el estudio y la importancia que tiene cultivar la inteligencia como una opción para acceder a mejores oportunidades en la vida. Tal como lo expresa (Gardner, 2011) "Probablemente el niño capta por primera vez los conceptos de trabajo y ciudadania en el colegio, y en ese sentido, es capaz de reflexionar sobre cómo desempeñar adecuadamente la función de alumno y la función de entregarse a su clase”(p.159), valores que a largo plazo se transposicionan a la sociedad en la cual se desenvuelve la persona. Por lo tanto, para lograr mejores caracteristicas en relación con un estudiante ideal "durante los primeros años escolares se debe hacer hincapié en las palabras y conductas que mejor registra la mente joven: modelos vivos convincentes e impresionantes que ejemplifiquen las razones y conductas deseables" (Gardner, 2011,p.159). 
Pregunta 13 (P13): ¿Qué aspectos considera que pueden afectar positiva o negativamente el aprendizaje de los niños, niñas y jóvenes de su colegio?

Figura 20. Respuestas pregunta 13

\begin{tabular}{|c|c|c|c|c|}
\hline $\begin{array}{l}\text { Respoestas } \\
\text { recurrentes }\end{array}$ & Color & $\begin{array}{c}\text { Numero de respoestas } \\
\text { por colegio }\end{array}$ & Total & Porcentaje \\
\hline $\begin{array}{l}\text { Las malas relaciones } \\
\text { interpersonales qoe } \\
\text { terminan en peleas, } \\
\text { rias, matooso e } \\
\text { irrespeto a las claves. }\end{array}$ & $\bar{X}$ & $10,23,13,18,7,15,9$ & 95 & $31.45 \%$ \\
\hline $\begin{array}{l}\text { Algoood maestros qoe } \\
\text { tienea mal cardeter o } \\
\text { proponea claves } \\
\text { dexmotivantes. }\end{array}$ & $\bar{x}$ & $3,11,11,8,5,1,17$ & 56 & $18.54 \%$ \\
\hline $\begin{array}{l}\text { Las paodillas y } \\
\text { probiemas alrededor } \\
\text { del colegio }\end{array}$ & $\mathrm{X}$ & $0,3,0,0,0,6,0$ & 9 & $295 \%$ \\
\hline $\begin{array}{l}\text { Problemas de cardcter } \\
\text { intrapervoeal como } \\
\text { baja avioestima y } \\
\text { pocos deseos de } \\
\text { estediar. }\end{array}$ & $\mathrm{X}$ & $3,7,14,3,4,12,7$ & 50 & $1655 \%$ \\
\hline $\begin{array}{l}\text { E1 convomo y coetacto } \\
\text { con las drogas. }\end{array}$ & $\bar{X}$ & $5,6,4,2,10,11,1$ & 39 & $1291 \%$ \\
\hline $\begin{array}{l}\text { El apoyo familar o is } \\
\text { falta del mirmo poede } \\
\text { infloir ea el apreadizaje }\end{array}$ & $\mathrm{X}$ & $4,3,5,9,3,2,6$ & 32 & $1059 \%$ \\
\hline $\begin{array}{l}\text { Pooitivamente } 105 \\
\text { docentes qoe ayodan a } \\
\text { aprender }\end{array}$ & $\mathrm{X}$ & $0,4,5,2,3,0,2$ & 16 & $5.29 \%$ \\
\hline $\begin{array}{l}\text { Pocitivamente algeas } \\
\text { actitudes } \\
\text { intrapervonales o } \\
\text { interpervonales que } \\
\text { facilitan el apreadizaje. }\end{array}$ & $\mathrm{X}$ & $0,0,2,0,1,10,1$ & 5 & $1.65 \%$ \\
\hline
\end{tabular}




\section{Descripción respuestas a la pregunta 13}

En relación con esta pregunta los estudiantes de la (LSB) manifiestan que las riñas, el mal ambiente escolar, el matoneo, el irrespeto a las clases, algunos maestros con mal carácter, clases des motivantes, el mal ambiente alrededor del colegio, las drogas, la baja autoestima y el escaso apoyo familiar son factores que afectan negativamente el aprendizaje. Como se explica en los resultados de las primeras dos preguntas de esta investigación el contexto en el cual se desenvuelven los estudiantes en la (LSB) tiene una incidencia notable en las posibilidades y calidad que pueden tener los estudiantes respecto a sus aprendizajes. Por esto, los planteles educativos distritales en esta localidad deben posibilitar algunos escenarios alternos al aula de clase que le permitan a los jóvenes aprovechar su tiempo libre en actividades educativas, deportivas y culturales que disminuyan el contacto con escenarios de carácter negativo. Por otro lado, hacer un énfasis en los planes de aula y currículos de las instituciones educativas en aspectos formativos relacionados con el aspecto emocional y ético de los estudiantes.

\section{Discusión}

Los planteles educativos en el distrito desde sus estructuras curriculares deben prestar atención a las necesidades que manifiestan los estudiantes en relación con sus motivaciones intrínsecas y extrínsecas para asistir a la escuela. Es notable que los currículos tradicionales enfatizan en el aprendizaje memorístico, el cual "busca en esencia la transmisión del conocimiento, acompañada de una asimilación acrítica por parte de los estudiantes" (Camacho, Borquez, Colindres, 2018, p.35). Sin embargo, al dejar de lado el punto de vista del educando, las posibilidades de afectar positivamente su vida con el acto educativo se reducen, ya que se desconoce las intencionalidades que llevan al estudiante al aula de clase y algunos factores que pueden disminuir sus aprendizajes. En este sentido coincido con (Gardner, 2012), en posibilitar una escuela que este centrada en la persona que aprende, que tenga en cuenta sus particularidades, intereses, historias de vida, proyectos a futuro y puntos de vista en la consolidación de los currículos. Considerar las situaciones que afectan negativamente al 
estudiante en el entorno escolar y fuera de él nos ayuda como instituciones educativas a generar mejores propuestas desde el ámbito emocional, curricular, académico y personal. Teniendo en cuenta que los contextos en los cuales se desarrolla el niño tienen una incidencia en la conducta, la cual es considerada por Piaget, (1999) como "un caso particular de intercambio entre el mundo exterior y el sujeto; pero contrariamente a los intercambios fisiológicos que son de orden material y suponen una trasformación interna de los cuerpos que se enfrentan, "las conductas" suponen dos aspectos esenciales: uno afectivo y otro cognoscitivo" (p.14). Esto implica, que cada estudiante tiene unas características individuales que lo han permeado en la realidad social en la cual se circunscribe, e inciden sustancialmente en su aproximación al proceso educativo desde el saber y desde la emoción que lo lleva al plantel educativo.

Considerando que la población escolar en la (LSB) en su gran mayoría pertenece a hogares monoparentales, que han migrado de diferentes zonas del país y con trabajos que oscilan entre lo formal y la informalidad (Porras, Sáenz y Ruiz, 2009), es muy común que los jóvenes pasen su tiempo en casa solos y con poco apoyo para las tareas, ya que sus tutores deben estar trabajando en horarios, a veces extensos. Frente a esta realidad es ideal que la escuela desarrolle espacios de acompañamiento académico y psicosocial desde lo cooperativo hacia estos jóvenes para disminuir las brechas en el aprendizaje y mejorar sus competencias en las distintas asignaturas. Este tipo de estrategias cooperativas disminuyen la competitividad en el aula de clase, propician metas desde lo educativo que pueden ser logradas por todos los estudiantes y motiva a los jóvenes en su participación activa en clases, ya que, al lograr los objetivos de aprendizaje y comprender las temáticas, fortalece su autoestima, lo invita a crecer cognitivamente y brinda una sensación de triunfo que abre el camino a nuevos aprendizajes, "considerando que la interdependencia social existe continuamente. Es el aspecto fundamental y más ubicuo del ser humano y afecta todas nuestras actividades, incluyendo la productividad, la calidad de nuestras relaciones y nuestra salud psíquica” (Johnson \& Johnson, 1999, p.18).

En esta misma línea, los contenidos a desarrollar, las metodologías al plantear las sesiones de trabajo, las estrategias didácticas, los procesos evaluativos y la forma en que el maestro 
concibe la enseñanza, el saber y aprendizaje, deben estar mediados por las percepciones que tienen los estudiantes de la clase. Del mismo modo, comprender la integralidad del ser que aprende, para encontrar formas posibles de aproximarse al estadio emocional y cognitivo que tiene el estudiante desde la mirada del maestro, puede ayudar a generar empatía en cada encuentro y así optimizar las relaciones interpersonales entre el educador y el educando, "considerando que vivir humanamente no es llegar a ser lo que uno es, sino todo lo contrario, ser otro, ser distinto" (Mélich, 2010, p.225), es decir, llegar a pensar en la fragilidad del que llega a nuestras clases como si nos afectara propiamente. Por lo tanto, estos aspectos mencionados son indispensables para el desarrollo del pensamiento desde las diferentes ventanas de aprendizaje, considerando que un cerebro que presenta disposición, trabajo constante, estímulos acordes a sus habilidades y variedad en los sentidos a trabajar, tiene mayores posibilidades de estructurar conexiones neuronales a largo plazo (Gardner,2016).

Por otro lado, es indispensable proponer o reestructurar las escuelas de padres en los colegios de la localidad tratando de ayudar a las familias interesadas en la formación integral de sus hijos, considerando que,

los niños imitan un amplio rango de conducta de los padres, incluyendo lo que hacen y cómo lo hacen, sus manierismos, como hablan y como gesticulan al hacerlo. Lo cual demuestra que la imitación tiene un valor enorme en el proceso de aprendizaje, pues lo acelera, lo hace en un tiempo más corto y además multiplica las oportunidades de aprender (Mora, 2013, p.47).

\section{Conclusiones}

La educación se transforma acorde a los cambios que las sociedades exigen, sin embargo, pocos son los avances que se han logrado en materia educativa en los colegios públicos a nivel de innovación pedagógica. Es de reconocer los esfuerzos de entidades como la universidad de los Andes, la fundación compartir y el Idep, quienes proponen algunos proyectos para sistematizar y reconocer las propuestas de algunos maestros estatales. Sin embargo, es 
necesario masificar las propuestas pedagógicas significativas, para que lleguen a los niños de localidades vulnerables y así aportar a la solución de las problemáticas que en este escrito se plantean. En este sentido, identificar las principales motivaciones que presentan los estudiantes en la (LSB) permite caracterizar las distintas problemáticas que se dejan de abordar desde el acto educativo, abre caminos a los maestros en relación con otras formas de ver el acto educativo y posibilita prácticas de enseñanza, rigurosas, pertinentes y situadas.

Aunque los colegios públicos en la (LSB) presentan situaciones complejas en sus realidades particulares, son escasas las intervenciones que las instituciones educativas realizan para abordar y dar solución a estas problemáticas, ya que el sentido de los planteles educativos se centra en el fortalecimiento de los aspectos académicos basados en el contenido, dejando de lado aspectos esenciales para el ser como la socio emocionalidad, los valores, los aspectos éticos y morales de los jóvenes desde su realidades personales. Por esto, se hace necesario identificar y caracterizar las particularidades que se presentan en cada colegio desde los aspectos antes mencionados para así brindar intervenciones pedagógicas pertinentes y con un sentido de transformación social. Un primer paso puede ser la consolidación de encuestas que nos permitan recolectar la mayor cantidad de información de los jóvenes en la localidad, para así dar respuesta desde la reestructuración de los currículos, las prácticas de enseñanza, las formas de evaluar y las interacciones en el aula de clase.

Por otro lado, es necesario que las facultades de educación superior propendan por la formación de los futuros educadores en el campo de las competencias socioemocionales, como un aspecto indispensable en contextos poblacionales que presentan diversas problemáticas, en el campo de la investigación, acción, reflexión en el aula de clase, como un componente necesario para aproximarse a los contextos educativos y así conocer las características de la población educativa. Considerando que factores como la ausencia de empatía, el desconocimiento por parte de algunos maestros de la realidad personal de los estudiantes y la ausencia de una evaluación integral de los aprendizajes afecta notablemente la motivación de los estudiantes en la (LSB). 
Hay diferentes factores que motivan a los estudiantes de la (LSB) en su asistencia a clases, los compañeros de estudio, los maestros que hacen agradables sus clases, los contenidos que se relacionan con su vida cotidiana y su ideales o metas. Estos factores, pueden ser identificados a través de instrumentos antes mencionados, que permitan a los colegios abordar las particularidades y así brindar procesos educativos pertinentes y que se puedan evaluar en el tiempo para optimizarlos. Ya que

en ocasiones, los intereses que motivan a los estudiantes a participar en el acto educativo están intrínsecamente relacionados con los beneficios que se adquieren a largo plazo por la participación en las clases. En este sentido, es necesario establecer una conexión entre las propuestas educativas, los postulados neurobiológicos de la emoción y la relación de los aprendizajes con la vida de los jóvenes. Esta perspectiva, invita al educador a generar un sentido en cada propuesta metodológica, en los contenidos seleccionados y en la visión holística de un estudiante con características particulares o diferenciadas. Por otro lado, se crea la necesidad de reflexionar en torno a los aspectos que deben ser abordados en la cotidianidad escolar; como son: los ambientes de aprendizaje, las necesidades emocionales, las expectativas de vida y la visión de persona que requiere la sociedad actual. (Piñeros, 2019, p.289)

El interaccionismo simbólico, como presupuesto epistémico y la teoría fundamentada como diseño de investigación aplicado en el ámbito educativo, brindan diversas posibilidades para describir e interpretar las percepciones que los jóvenes han elaborado a través de la relación con sus contextos, en la (LSB) se consolida como una apuesta metodológica que se puede utilizar para hacer investigación situada o sistematizar experiencias que los docentes hayan desarrollado. En los contextos educativos de la (LSB) sería ideal el trabajo por proyectos, que puedan describir a partir de las interacciones de los estudiantes con su interpretación de los signos y símbolos que los han afectado, nuevos caminos para reelaborar los procesos de enseñanza, saber y aprendizaje en la escuela. 
La pedagogía y la didáctica como campos de conocimiento de la educación pueden aportar a la renovación de las posibilidades de enseñanza que se han planteado en las instituciones educativas. Por lo tanto, deben estar en continua reflexión y cambio acorde a las modificaciones que se presentan en nuestras sociedades. Estas reflexiones deben ser propuestas por los educadores, estudiantes y padres de familia, desde un proceso de indagación que nos permita fortalecer el saber pedagógico, el saber didáctico y el saber ser, asumiendo la pedagogía como la reflexión teórico- práctica sobre la educabilidad la enseñabilidad y la educabilidad. Y la didáctica como la disciplina teórica que reflexiona sobre la enseñanza, el saber y el aprendizaje (Camilloni, 2008).

Según las respuestas de los estudiantes en la (LSB) los docentes son mediadores indispensables para que se presente la motivación, asistencia y participación por parte de los estudiantes en los diferentes momentos educativos. Sin embargo, también pueden considerarse como factores desmotivantes en la medida que no reflexionen sobre el acto educativo. Desde esta perspectiva, es necesario que los docentes se capaciten continuamente, fortalezcan sus competencias socioemocionales, profundicen en los nuevos retos que traen los niños de estas generaciones y renueven continuamente sus posibilidades didácticas de trabajo.

El trabajo colaborativo según los resultados de la investigación debe ser estimulado desde las primeras etapas de vida, como una oportunidad para aprender de la diferencia, para alejarse de la individualidad, del pensamiento competitivo y para generar habilidades interpersonales que nos permitan comprender que cada persona tiene fortalezas en diferentes campos de saber y que la escuela no es una competencia que compare a sus participantes, por el contrario es un escenario que debe despertar las cualidades personales a través del trabajo en equipo. Es recurrente que los estudiantes encuestados manifiestan asistir al colegio para compartir con sus compañeros, como un elemento necesario en relación con su bienestar emocional, pero también como un factor que posibilita mejores oportunidades de aprendizaje. 


\section{Referencias}

Blumer, H. (1982). El interaccionismo simbólico: perspectiva y método. Barcelona: Hora S.A.

Camacho, C. A., Bórquez, I. L., \& Colindres, I. M. (2018). La educación Lasallana para el siglo XXI. Bogotá-Colombia: Ediciones Unisalle.

Camilloni, A. D. (2008). El saber didáctico. Buenos Aires: Paidós.

Chaux, E. (2011): "Múltiples perspectivas sobre un problema complejo: comentarios sobre cinco investigaciones en violencia escolar". Psykhe, 79-86.

CIDH. (2015). Violencia, niñez y crimén organizado. Washington D. C.: Organización de estados americanos.

Dehaene, S. (2019). ¿Cómo aprendemos? Argentina: Siglo Veintiuno Editores.

Gardner, H. (1993). Estructuras de la mente la teoría de las inteligencias múltiples. Nueva York: Basic Books.

Gardner, H. (2007). Las cinco mentes del futuro. Barcelona: Ediciones Paidós Ibérica, S.A.

Gardner, H. (2011). Verdad, Belleza y Bondad reformuladas. Barcelona: Paidós.

Gardner, H. (2012). El desarrollo y la educación de la mente. Barcelona- España: Paidós.

Gardner, H. (2016). La mente no escolarizada: Cómo piensan los niños y cómo deberían enseñar en las escuelas. Barcelona-España: paidós. 
Gardner, H., \& Davis, K. (2014). La generación APP. Barcelona. España: Espasa Libros, S.L.U.

Gibbs, G. (2012). El análisis de datos cualitativos en investigación cualitativa. MadridEspaña: Ediciones Morata.

Goleman, D. (2012). El cerebro y la inteligencia emocional. Barcelona-España: Ediciones B, S.A.

Hurtado, J. B., \& Tercero, M. J. (2010). "Las corrientes pedagógicas contemporáneas y los estilos de enseñanza en la educación física". Investigación Educativa, 79-104.

Johnson, D., \& Johnson, R. (1999). Aprender juntos y solos. Buenos Aires: Grupo Editorial Aique S. A. .

Kandel, E., Schwartz, J., \& Jessel, T. M. (1997). Neurociencia y conducta. Madrid-España: Pearson, educación, S.A.

López, H. C. (2012). Neuro aprendizaje una propuesta educativa. Bogotá: Ediciones de la U.

Marzano, R., \& Pickering, D. (2005). Dimensiones del aprendizaje: manual para el maestro. México: Iteso.

Mélich, J. C. (2010). Ética de la compasión. España: Herder Editorial.

Mora, F. (2013). Neuroeducación solo se puede aprender aquello que se ama. España: Alianza editorial S.A.

Mounier, E. (1974). Obras, tomo 1 1931- 1939. Barcelona: Editorial Laia, S.A. 
Neira, M. G. (2010). "El currículo de educación física en la perspectiva cultural: fundamentos y práctica pedagógica". Horizontes Educacionales., 49-67.

Piaget, J. (1984). El criterio moral en el niño. Barcelona: Ediciones Martínez Roca S.A.

Piaget, J. (1999). Psicología de la inteligencia. Argentina: Editorial psique.

Piñeros, S. J. (20 de enero de 2019). Pedagogía de la biomotricidad: orientaciones didácticas basadas en el buen vivir. Tesis Doctoral. Bogotá, Bogotá, Colombia: Universidad de la Salle.

Porras, M. N., Sáenz, N. P., \& Ruiz, L. J. (febrero de 2009). "Las transiciones curriculares de la básica primaria a la básica secundaria y su incidencia en el derecho a la educación en Bogotá: estudios de caso" Tesis de maestría. Bogotá, Colombia.

Santomé, J. T. (1998). Globalización e interdisciplinariedad: el currículo integrado. Madrid: Morata, S.L.

Skinner, B. (1974). Sobre el conductismo. Nueva York: Fontanella, S.A.

Strauss, A., \& Corbin, J. (2002). Bases de la investigación cualitativa. Técnicas y procedimientos para desarrollar la teoría fundamentada. Colombia: Universidad de Antioquia. 
REVISTA INTERNACIONAL DE PEDAGOGÍA E INNOVACIÓN EDUCATIVA

Volumen 2. Número 1. Enero - Junio 2022 ISSN: 2745-0341 (En línea) 